Retrospective Evaluation

\title{
e Outcome of Percutaneous Lumbar Synovial Cyst Rupture in Patients with Lumbar Radiculopathy
}

Yashar Eshraghi, MD, Vimal Desai, MD, Calvin Cajigal Cajigal, MD, and Kutaiba Tabbaa, MD

From: Case Western Reserve University/MetroHealth Medical Center Cleveland, $\mathrm{OH}$

Address Correspondence: Yashar Eshraghi, MD Case Western Reserve University/MetroHealth Medical Center Anesthesiology 2500 MetroHealth Drive Cleveland, $\mathrm{OH}$ E-mail:

yashar.eshraghi@gmail.com

Disclaimer: There was no external funding in the preparation of this manuscript.

Conflict of interest: Each

author certifies that he or

she, or a member of his or

her immediate family, has no

commercial association (i.e., consultancies, stock ownership, equity interest, patent/

licensing arrangements, etc.) that might pose a conflict of interest in connection with the submitted manuscript.

Manuscript received: 03-17-2015

Revised manuscript received: 10-16-2015

Accepted for publication: 03-15-2016

Free full manuscript: www.painphysicianjournal.com
Background: Lumbar synovial cysts can result from spondylosis of facet joints. These cysts can encroach on adjacent nerve roots, causing symptoms of radiculopathy. Currently the only definitive treatment for these symptoms is surgery, which may involve laminectomy or laminotomy, with or without spinal fusion. Surgery has been reported to successfully relieve radicular pain in $83.5 \%$ of patients by Zhenbo et al. Little information is available concerning the efficacy and outcome of percutaneous fluoroscopic synovial cyst rupture for treatment of facet joint synovial cysts.

Objective: The goal of this investigation was to assess the efficacy of fluoroscopically guided lumbar synovial cyst rupture, in particular for its relief of radicular symptoms and its potential to reduce the need for surgical intervention.

Study Design: Retrospective evaluation of a case series.

Setting: University hospital and urban public health care system.

Methods: With approval from the Institutional Review Board of Case Western Reserve University/ MetroHealth Medical Center, we reviewed the medical charts of patients with lumbar radiculopathy who underwent percutaneous lumbar synovial cyst rupture. The 30 patients in the cohort were treated by one pain specialist between 2006 and 2013. These patients were diagnosed with moderate to severe lower back pain, radiculopathy, and ranged in age from 42 to 80 years. Patients were followed up for a minimum of 6 months and up to 24 months. Pre- and post-procedure pain assessments were reviewed by clinical chart review. In addition post-procedure pain assessments and duration of pain relief were obtained with telephone interviews. Pain had been reported by the patients using a numeric rating scale of $0-10(0=$ no pain; $10=$ worst possible pain). Charts were reviewed to determine if surgery was eventually performed to correct radicular symptoms.

Results: More than 6 months of pain relief was achieved in 14/30 patients (46\%) and between one and 6 months of pain relief was achieved in $7 / 30$ patients $(23.3 \%)$. Nine patients $(30.0 \%)$ had recurrence of the synovial cyst requiring repeat rupture and 6 patients $(20.0 \%)$ required surgical intervention for cyst removal. A Wilcoxon signed-rank test demonstrated that the difference in numeric pain rating scale scores before and after the procedure was statistically significant $(P<$ 0.0001). The average pain reduction was $71.2 \%$. No complications were reported.

Limitations: The results are limited by the retrospective nature of the data collection and the lack of detailed information regarding patients' functional improvement.

Conclusions: Rupture of percutaneous lumbar synovial cysts in patients with lumbar radiculopathy was associated with immediate relief of radicular symptoms. In $80 \%$ of the patients, synovial cyst rupture eliminated the need for surgical interventions over the measured term. This minimally invasive procedure helps relieve pain in a subset of a patient population associated with these characteristics and is useful for management of this condition. Cyst expansion and failure to rupture with possible neuronal compression are the potential complications of this procedure. This complication did not occur in the study population.

Key words: Fluoroscopically guided lumbar synovial cyst rupture, lumbar synovial cyst, lumbar zygapophyseal joint cyst, nonsurgical intervention, radiculopathy, spondylosis

Pain Physician 2016; 19:E1019-E1025 
V osschulte (1) and Pendleton et al (2) first described extradural spinal nerve compression resulting from a lumbar facet cyst about 50 years ago. Although these cysts are considered benign, patients can present with radiculopathy and low back pain in association with spinal stenosis and/or direct nerve root compression. Synovial cyst of the lumbar spinal facet joints is one of the least common etiologies of lumbar spine radiculopathy. Synovial cysts have been described in association with both facet joints and the ligamentum flavum. However, the majority of facet joint cysts appear to originate from the joint capsule in association with degenerative spondylosis affecting the facet joints (3-6).

There is a paucity of comprehensive evidence on the appropriate management of symptomatic lumbar synovial cysts. A nonsurgical or surgical approach can be chosen. Alternative nonsurgical treatments include bed rest, physical therapy, chiropractic care, acupuncture, oral pain medications, bracing, and lumbar spinal injections (7). Most of the studies investigating nonsurgical management of lumbar synovial cysts included small sample sizes. Bureau et al (8) reported 12 percutaneous steroid injections and subsequent pain relief in $75 \%$ of patients, whereas Slipman et al (9) and Parlier-Cuau et al (10) studied 14 and 30 steroid injections, respectively, and reported symptomatic relief in up to one-third of patients.

The only study of nonsurgical treatment with a large sample was reported by Matha et al (11), with 101 patients who demonstrated successful cyst rupture in $81 \%$ of cases; 55 patients $(54 \%$ ) subsequently required surgery because of inadequate symptom relief. There was no significant difference in pain among the patients who received only injections and those who underwent subsequent surgical intervention (11). Other studies with larger sample sizes considered surgical management and suggested decompression laminectomy and cyst excision with possible simultaneous fusion as treatment modalities (12-18).

Based on inconsistent literature reports on the treatment of lumbar synovial cysts, we looked to evaluate the potential of a non-invasive technique to relieve pain. In our study, the efficiency and safety of fluoroscopically guided lumbar synovial cyst rupture was evaluated in 30 patients with radicular symptoms. The analysis paid particular attention to relief of radicular symptoms and potential avoidance of surgical intervention. In addition, this report will provide a thorough description of the lumbar synovial cyst rupture procedure because technical details are lacking in the literature.

\section{Methods}

With approval from the Institutional Review Board of Case Western Reserve University/MetroHealth Medical Center, we performed a retrospective chart analysis of 30 patients with moderate to severe lumbar radiculopathy who underwent percutaneous lumbar synovial cyst rupture. All of the procedures were performed by one pain specialist between 2006 and 2013.

Data collected included the patients' height, weight, and age; the synovial cyst location, the success or failure of rupture; and subsequent surgical treatment. The patient's clinical symptoms correlated with magnetic resonance imaging (MRI) studies documenting the presence of a synovial cyst at the corresponding level and side of symptoms (Fig. 1). Pre- and postprocedure pain assessments were reviewed with clinical chart review for patients who underwent percutaneous lumbar synovial cyst rupture with lumbar radiculopathy. A numeric rating scale of $0-10(0=$ no pain; $10=$ worst possible pain) was used to evaluate the radicular pain. Data analysis was conducted using a Wilcoxon signedrank test and a sample size of 30 patients provided statistical significance that it fulfilled the power analysis.

Telephone interviews were performed at a mean of 44.16 months (11 to 83 months) following the primary procedure to assess the presence or recurrence of radicular symptoms (using the same numeric pain scale), the duration of pain relief, and to determine if any surgical intervention had followed the synovial cyst rupture procedure. Verbal informed consent was obtained from all the patients prior to the telephone interview.

\section{Procedure Technique}

Patients were placed in the prone position. The procedure was performed under aseptic conditions. A 22 gauge 10 to $15 \mathrm{~cm}$ spinal needle was introduced into the inferior joint recess below the cyst under fluoroscopic guidance. Aspiration of synovial fluids was achievable in a few cases if the cyst neck was widely connected to the facet joint. Next $1-2 \mathrm{~mL}$ of (nonionic contrast) iohexol $300 \mathrm{mg} / \mathrm{mL}$ was injected into the facet joint to identify intraarticular positioning of the needle and filling of the cyst; this finding confirmed the diagnosis of lumbar facet synovial cyst. Subsequently, the contrast and the synovial fluids were aspirated. Preservative-free bupivicaine $0.5 \%(1-2 \mathrm{~mL})$ was injected and trapped for $3-4$ minutes. 


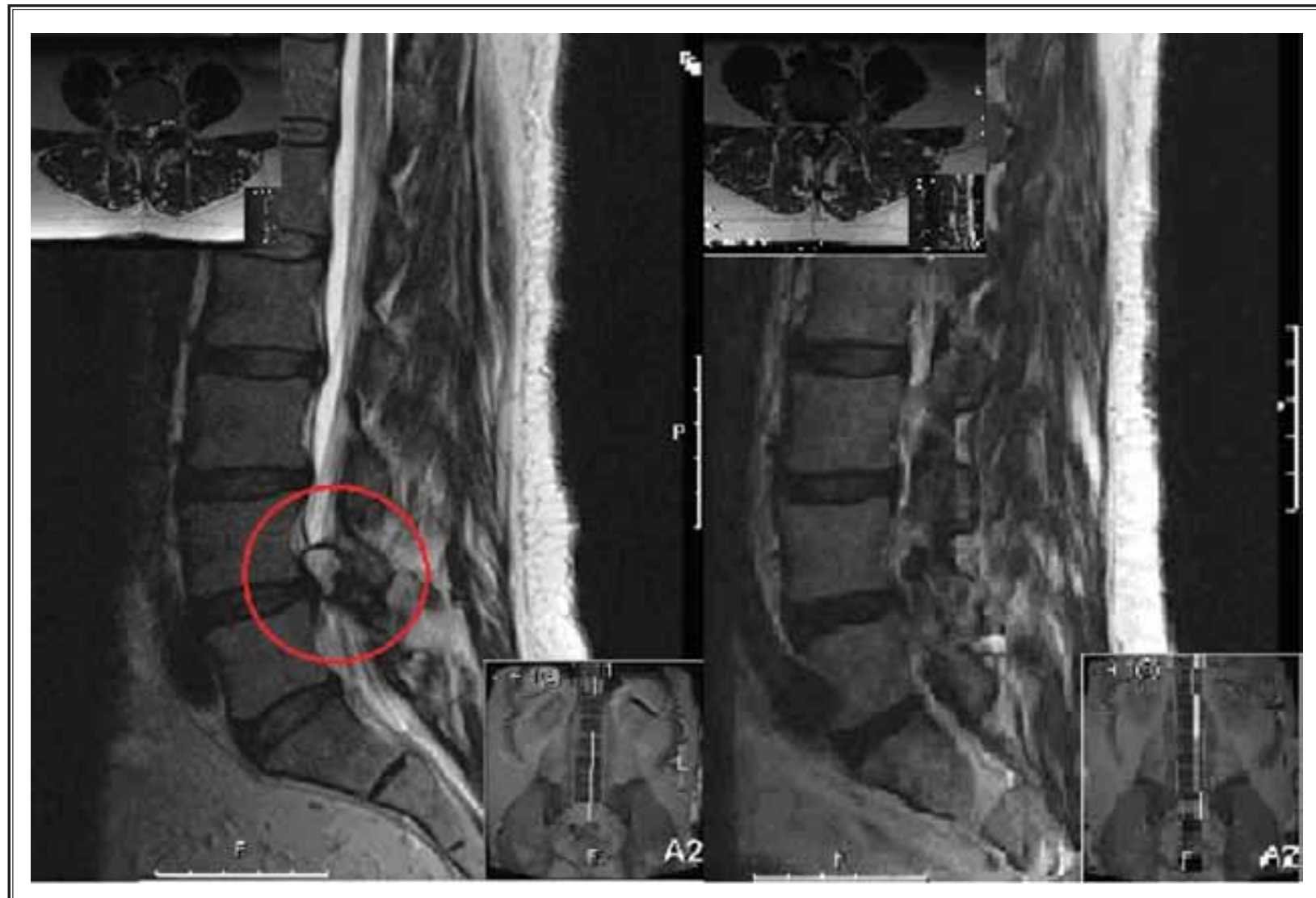

Fig. 1. MRI imaging of a patient with lumbar synovial cyst pre and post synovial cyst rupture.

Then, as much as $10 \mathrm{~mL}$ of normal saline (sodium chloride $0.9 \%$ ) was injected in an attempt to rupture the cyst until loss of resistance was achieved. Subsequently, another $2-4 \mathrm{~mL}$ of iohexol $300 \mathrm{mg} / \mathrm{mL}$ was injected to identify free flow of the dye from the joint to the epidural space anteriorly and posteriorly. After free flow of the dye was confirmed, $80-120 \mathrm{mg}$ methylprednisolone acetate (DepoMedrol) with $1-2 \mathrm{~mL}$ of preservative-free bupivacaine $0.5 \%$ was injected (Fig. 2).

\section{Results}

The charts of 30 patients who underwent lumbar synovial cyst rupture were reviewed, and telephone interviews were conducted to obtain post-procedure information. We were unable to contact one patient for the follow-up telephone interview.

The patients ranged in age from 42 to 80 years (mean $=58.7$ years; SD $=11.1$ years), and $63.3 \%$ of the patients were women. The average body mass index of the patients was 30.6 (Table 1). The majority of the sy- novial cysts were located at the L4-L5 level (20/30). The less frequent cysts were located at L5-S1 (4/30), L3-L4 (3/30), and L2-L3 (3/20).

The majority of patients $(76.7 \% ; 23 / 30)$ were taking opioid treatment prior to the procedure; at the time of the follow-up interview, only $41.3 \%$ (12/29) of patients were still taking opioids after the synovial cyst rupture. The average follow-up time was 44.1 months ( $S D=22.6$ months; median = 38.5 months). More than 6 months of pain relief was achieved in 14/30 (46.0\%) patients, and between one and 6 months of pain relief was achieved in 7/30 (23.3\%) patients undergoing facet cyst rupture (Fig. 3 ).

Follow-up revealed that 9 patients $(30.0 \%)$ had synovial cyst recurrence, requiring repeat rupture, and 6 patients $(20.0 \%)$ required surgical intervention for cyst removal (Table 2). The attempted synovial cyst rupture procedure was unsuccessful in one patient.

Wilcoxon signed rank test demonstrated that the difference in numeric pain scores before and after the 


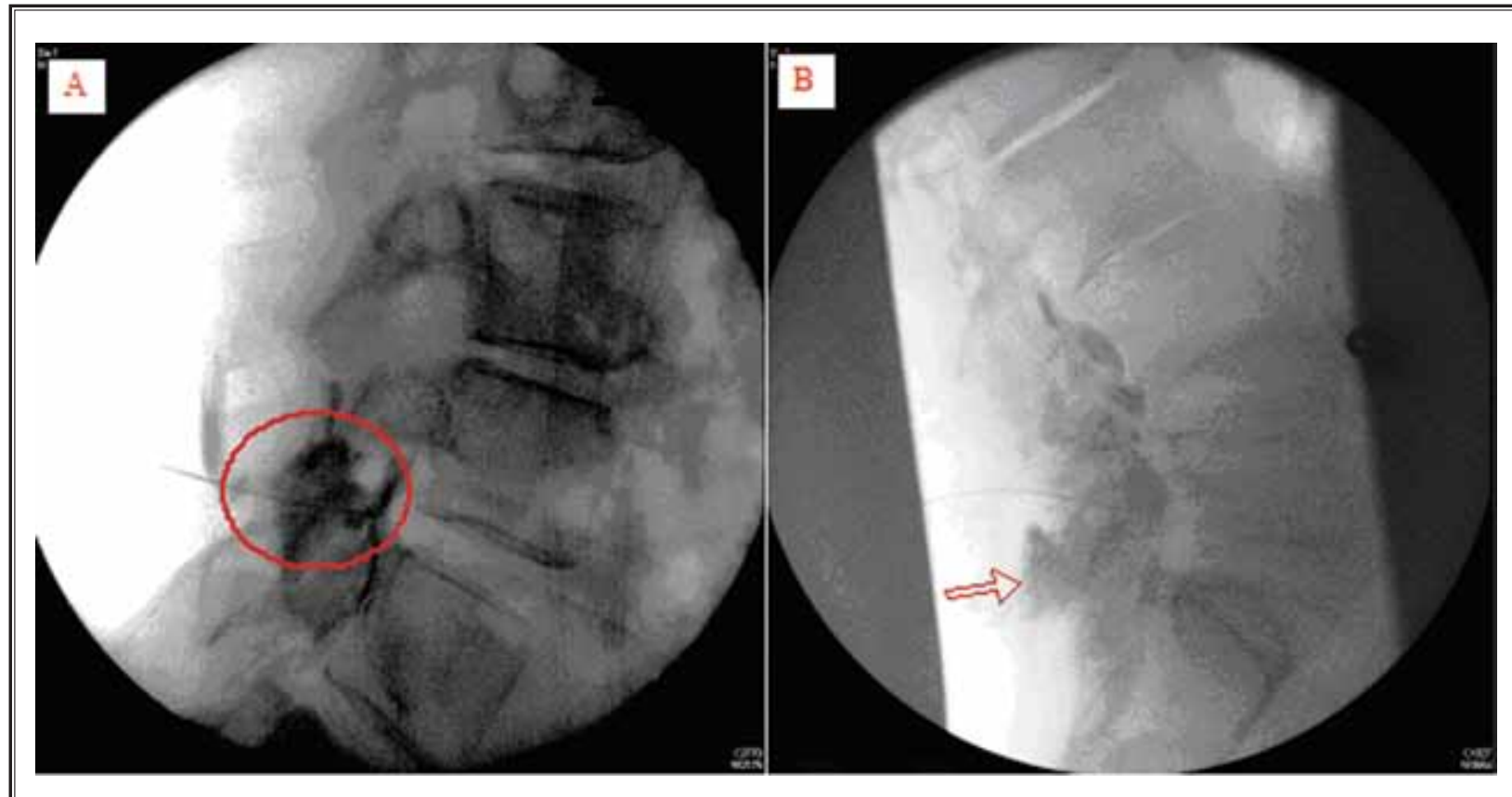

Fig. 2. Image A: Non-ionic contrast injected into the facet joint to identify intraarticular positioning of the needle and filling of the cyst; this finding confirmed the diagnosis of lumbar facet synovial cyst. Image B: Normal saline was injected in an attempt to rupture the cyst and non-ionic contrast was utilized to identify the free flow of the dye into the epidural space.

Table 1. Demographic characteristics of the patients underwent percutaneous lumbar synovial cyst rupture.

\begin{tabular}{|l|c|c||}
\hline \hline GENDER & Total Number & Percent of Total \\
\hline Male & 11 & $36.7 \%$ \\
\hline Female & 19 & $63.3 \%$ \\
\hline DEMOGRAPHICS & Average & Standard Deviation \\
\hline Age (years) & 58.7 & 11.1 \\
\hline Weight (Kg) & 88.8 & 22.0 \\
\hline BMI & 30.6 & 6.0 \\
\hline
\end{tabular}

procedure was statistically significant $(P<0.0001)$ (Fig. 4). The average pain reduction was $71.2 \%$ (Table 3 ). No complications were reported.

\section{Discussion}

The incidence of lumbar synovial cyst is $0.65 \%$ to $10 \%$ among patients with radiculopathy and/or lumbar pain who are referred for MRI of the lumbar spine $(12,16,19-21)$. The most frequent location is at the L4-L5 level, similar to the findings in our case series (7).

There is controversy as to whether a nonsurgical or surgical approach is the appropriate treatment for these cysts $(8,12,22-24)$. Synovial cysts that do not re- spond to nonsurgical and noninvasive treatments are referred for surgical management, which may include facetectomy or laminectomy with or without spinal fusion, flavectomy, cyst excision, and microsurgery techniques $(12,23,25)$. Zhenbo et al $(22)$ showed a mean pain improvement rate of $83.5 \%$ at one year post surgery and $75.6 \%$ at final visit after hemilaminectomy of lumbar intraspinal synovial cysts. Several surgical techniques are described with no significant difference in outcomes $(14,25-27)$. The surgical complication rates are reported up to $1.6 \%$ including dural tear, spinal nerve injury, epidural hematoma, seroma, cyst recurrence, and deep venous thrombosis $(12,25,28)$.

In spite of acceptable outcomes with surgical resection, several authors support nonsurgical intervention due to complications, cost, and potential hazards of major surgery $(7,9,10)$. Nonsurgical management may include observation, analgesics, bracing, chiropractic therapy, physical therapy, transcutaneous electrical nerve stimulation (TENS), interlaminar epidural steroid injections, transforaminal epidural steroid injection, and facet joint injection, with or without cyst rupture $(29,30)$. Amoretti et al $(31)$ described $54 \%$ satisfaction with a long-lasting result from computed tomography (CT)-guided intra-cystic and intra-articular steroid injec- 


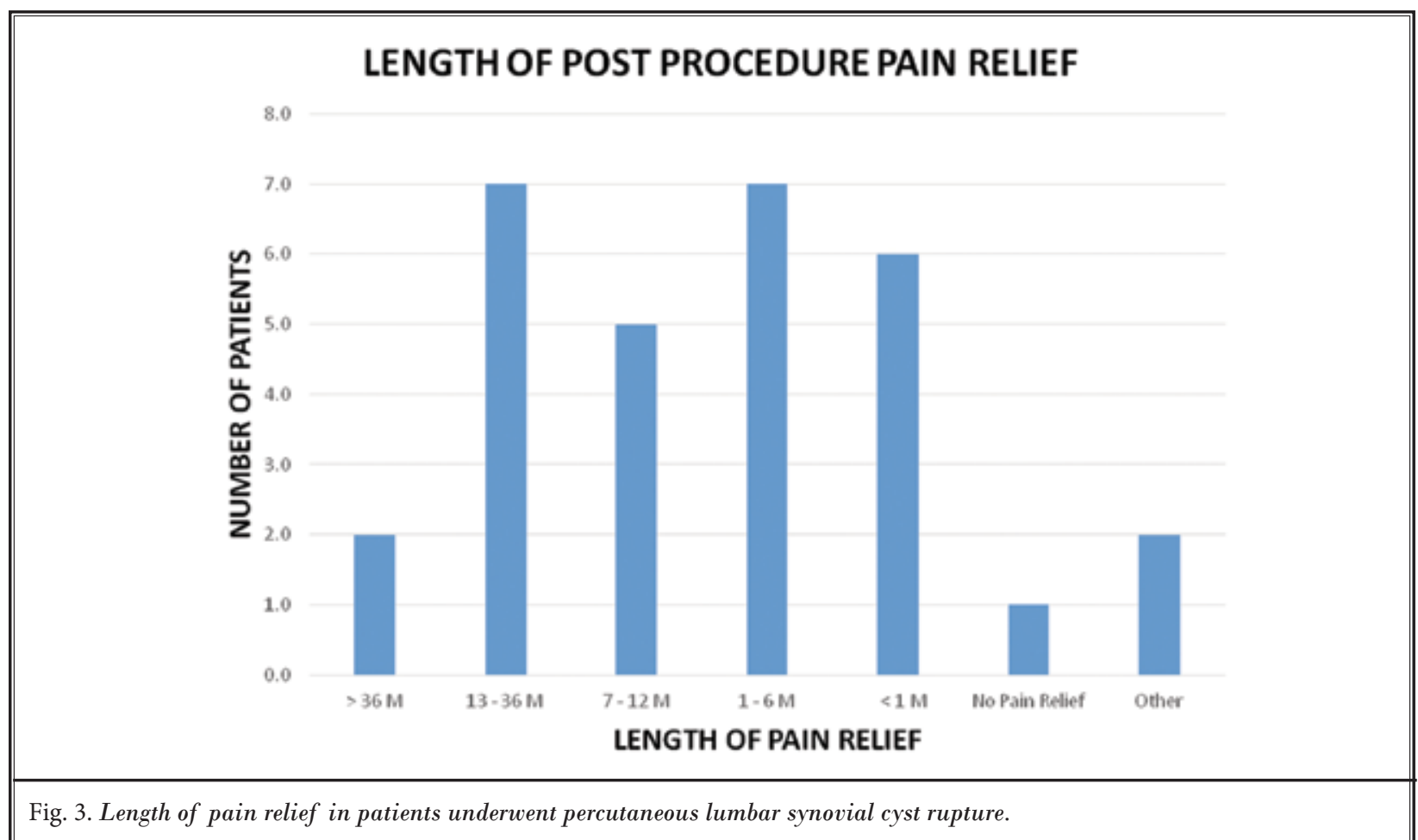

Table 2. Clinical features of the patients underwent percutaneous lumbar synovial cyst rupture.

\begin{tabular}{|l|c|c|c||}
\hline & Surgery & Recurrence & $\begin{array}{c}\text { Immediate } \\
\text { pain relief }\end{array}$ \\
\hline Yes & 6 & 9 & 28 \\
\hline No & 24 & 21 & 2 \\
\hline Mean & 0.20 & 0.30 & 0.93 \\
\hline Standard Error & 0.07 & 0.09 & 0.05 \\
\hline Confidence Interval & 0.15 & 0.17 & 0.09 \\
\hline
\end{tabular}

tions following the first intra-cystic and intra-articular steroid injections ( $n=65)$, and $20.8 \%$ satisfaction with a long-lasting result from a second intervention among 120 patients with symptomatic lumbar facet joint cysts. Bureau et al (8) reported almost similar results after 12 percutaneous steroid injections with pain relief in $75 \%$ of patient. In addition, Parlier-Cuau et al (10) showed excellent or good symptomatic relief in $67 \%$ of patients who underwent facet intraarticular steroid injections after one month and $50 \%$ after 6 months. Slipman et al (9) demonstrated $28.6 \%$ success rate with fluoroscopically guided facet joint steroid injections and cyst rupture .

Although various minimally invasive treatment approaches have been described, several authors sup-
Table 3. Pain score comparison between the patients before and after synovial cyst rupture procedure.

\begin{tabular}{||c|c|c|c||}
\hline \multicolumn{2}{||c|}{ Pain Before } & \multicolumn{2}{c|}{ Pain After } \\
\hline Mean & $\begin{array}{c}\text { Standard } \\
\text { Deviation }\end{array}$ & Mean & $\begin{array}{c}\text { Standard } \\
\text { Deviation }\end{array}$ \\
\hline 7.3 & 1.7 & 2.1 & 1.6 \\
\hline \multicolumn{3}{|c|}{ Average Pain Reduction $=71.2 \%$} \\
\hline
\end{tabular}

port the therapeutic value and low morbidity of image guided symptomatic lumbar synovial cyst rupture. Both CT guided and fluoroscopic guided percutaneous techniques have been described with no significant difference in the outcomes $(8,11,32-35)$. The recent meta-analysis by Shuang et al (36) included 26 studies and showed $55.8 \%$ success rate to percutaneous lumbar facet joint cyst resolution procedures with $38.6 \%$ requiring surgical intervention. Elderly and high risk patients who are not good candidates for surgical management due to multiple comorbidities can benefit from this minimally invasive treatment. Furthermore, percutaneous rupture of zygapophyseal joint cysts will decrease intraforaminal stenosis and consequently result in improvement or resolution of radicular symptoms. The 


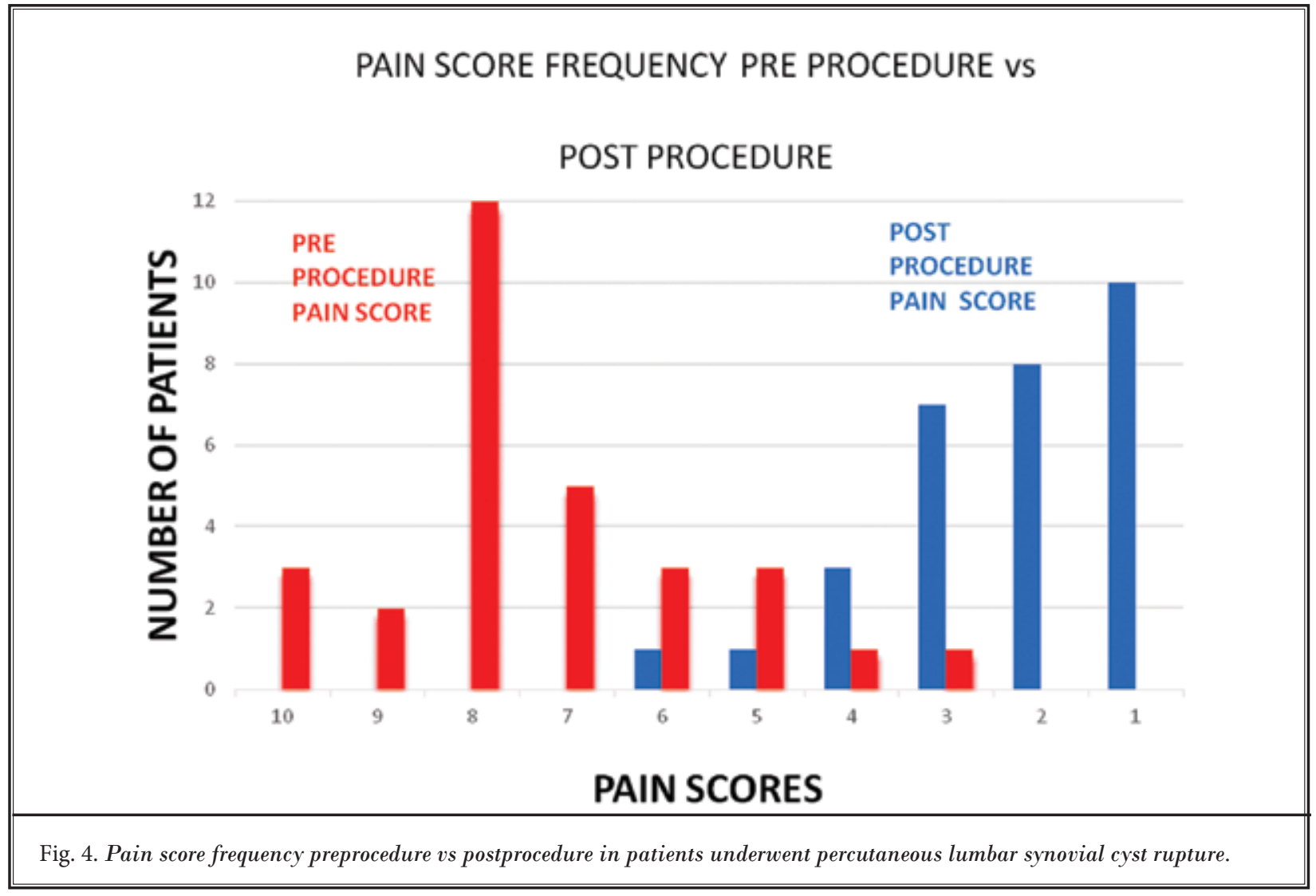

intraforaminal stenosis may return in the long term due to deterioration of articular degenerative changes or cyst recurrence that might require a surgical approach. However, patients who underwent lumbar synovial cyst rupture may benefit from avoidance or delaying invasive surgical intervention.

Here, we further demonstrate successful results for rupture of percutaneous lumbar synovial cysts including immediate and long-term relief of radicular symptoms. In $80 \%$ of the patients in our retrospective study synovial cyst rupture prevented future surgical interventions in the long term. This case series shows a successful clinical outcome for patients with lumbar synovial cyst rupture.

These results are limited by the retrospective nature of the data collection and the lack of detailed information regarding the improvement in patients' functional status. To provide further evidence of the efficacy of the percutaneous lumbar synovial cyst rupture procedure, there is a need for a randomized controlled trial including a well-designed control procedure with a larger sample size to match the power required.

This minimally invasive procedure does help to relieve pain in a subset of a patient population associated with these characteristics and is useful for management of this condition. The main potential complications of the procedure are cyst expansion and failure to rupture with possible neuronal compression. We did not encounter this complication in our study population. As an expert opinion, we believe that the enlarged cyst following expansion with normal saline can potentially be easily accessible through the corresponding foraminal level when the transforaminal epidural approach is used to decompress the cyst. 


\section{References}

1. Vosschulte K BG. Anatomische and funktinonelle Untersuchungen iiber den Bandscheibenprolaps. Langenbecks Arch Klin 1950; 265:S329-S355.

2. Pendleton B, Carl B, Pollay M. Spinal extradural benign synovial or ganglion cyst: Case report and review of the literature. Neurosurgery 1983; 13:322-326.

3. Abdullah AF, Chambers RW, Daut DP. Lumbar nerve root compression by synovial cysts of the ligamentum flavum. Report of four cases. J Neurosurg 1984; 6o:617-620.

4. Brish A, Payan HM. Lumbar intraspinal extradural ganglion cyst. J Neurol Neurosurg Psychiatry 1972; 35:771-775.

5. Kao CC, Uihlein A, Bickel WH, Soule $\mathrm{EH}$. Lumbar intraspinal extradural ganglion cyst. J Neurosurg 1968; 29:168-172.

6. Kurz LT, Garfin SR, Unger AS, Thorne $\mathrm{RP}$, Rothman RH. Intraspinal synovial cyst causing sciatica. J Bone Joint Surg Am 1985; 67:865-871.

7. Shah RV, Lutz GE. Lumbar intraspinal synovial cysts: Conservative management and review of the world's literature. Spine J 2003; 3:479-488.

8. Bureau NJ, Kaplan PA, Dussault RG. Lumbar facet joint synovial cyst: Percutaneous treatment with steroid injections and distention -- clinical and imaging follow-up in 12 patients. Radiology 2001; 221:179-185.

9. Slipman CW, Lipetz JS, Wakeshima Y, Jackson HB. Nonsurgical treatment of zygapophyseal joint cyst-induced radicular pain. Arch Phys Med Rehabil 2000; 81:973-977.

10. Parlier-Cuau C, Wybier M, Nizard R, Champsaur P, Le Hir P, Laredo JD. Symptomatic lumbar facet joint synovial cysts: Clinical assessment of facet joint steroid injection after 1 and 6 months and long-term follow-up in 30 patients. Radiology 1999; 210:509-513.

11. Martha JF, Swaim B, Wang DA, Kim DH, Hill J, Bode R, Schwartz CE. Outcome of percutaneous rupture of lumbar synovial cysts: A case series of 101 patients. Spine ] 2009; 9:899-904.

12. Lyons MK, Atkinson JL, Wharen RE, Deen HG, Zimmerman RS, Lemens SM. Surgical evaluation and management of lumbar synovial cysts: The Mayo Clinic experience. J Neurosurg 2000; 93:53-57.

13. Epstein NE. Lumbar laminectomy for the resection of synovial cysts and co- existing lumbar spinal stenosis or degenerative spondylolisthesis: An outcome study. Spine (Phila Pa 1976) 2004; 29:1049-1055; discussion 1056.

14. Khan AM, Synnot K, Cammisa FP, Girardi FP. Lumbar synovial cysts of the spine: An evaluation of surgical outcome. J Spinal Disord Tech 2005; 18:127-131.

15. Howington JU, Connolly ES, Voorhies RM. Intraspinal synovial cysts: 10-year experience at the Ochsner Clinic. J Neurosurg 1999; 91:193-199.

16. Banning CS, Thorell WE, Leibrock LG. Patient outcome after resection of lumbar juxtafacet cysts. Spine (Phila Pa 1976) 2001; 26:969-972.

17. Weiner BK, Torretti J, Stauff M. Microdecompression for lumbar synovial cysts: An independent assessment of long term outcomes. J Orthop Surg Res 2007; 2:5.

18. Salmon B, Martin D, Lenelle J, Stevenaert A. Juxtafacet cyst of the lumbar spine. Clinical, radiological and therapeutic aspects in 28 cases. Acta Neurochir (Wien) 2001; 143:129-134.

19. Boviatsis EJ, Stavrinou LC, Kouyialis AT, Gavra MM, Stavrinou PC, Themistokleous M, Selviaridis P, Sakas DE. Spinal synovial cysts: Pathogenesis, diagnosis and surgical treatment in a series of seven cases and literature review. Eur Spine ] 2008; 17:831-837.

20. Epstein NE. Lumbar synovial cysts: A review of diagnosis, surgical management, and outcome assessment. J Spinal Disord Tech 2004; 17:321-325.

21. Doyle AJ, Merrilees M. Synovial cysts of the lumbar facet joints in a symptomatic population: Prevalence on magnetic resonance imaging. Spine (Phila Pa 1976) 2004; 29:874-878.

22. Zhenbo Z, Huanting L, Jin W, Haifeng G, Yuan F, Ming L. Hemilaminoplasty for the treatment of lumbar intraspinal synovial cysts (LISCs) and literature review. Eur Spine J 2014;doi:10.1007/ soo586-014-3570-x.

23. Khan AM, Girardi F. Spinal lumbar synovial cysts. Diagnosis and management challenge. Eur Spine J 2006; 15:1176-1182.

24. Bjorkengren AG, Kurz LT, Resnick D, Sartoris DJ, Garfin SR. Symptomatic intraspinal synovial cysts: Opacification and treatment by percutaneous injection. AJR Am J Roentgenol 1987; 149:105-107.

25. Trummer $M$, Flaschka $G$, Tillich $M$,
Homann CN, Unger F, Eustacchio S. Diagnosis and surgical management of intraspinal synovial cysts: Report of 19 cases. J Neurol Neurosurg Psychiatry 2001; 70:74-77.

26. Sabo RA, Tracy PT, Weinger JM. A series of 60 juxtafacet cysts: Clinical presentation, the role of spinal instability, and treatment. J Neurosurg 1996; 85:560-565.

27. Indar R, Tsiridis E, Morgan M, Aldham $\mathrm{CH}$, Hussein AA. Intraspinal lumbar synovial cysts: Diagnosis and surgical management. Surgeon 2004; 2:141-144.

28. Bhushan C, Hodges FJ, 3rd, Wityk JJ. Synovial cyst (ganglion) of the lumbar spine simulating extradural mass. Neuroradiology 1979; 18:263-268.

29. Hemminghytt $S$, Daniels DL, Williams AL, Haughton VM. Intraspinal synovial cysts: Natural history and diagnosis by CT. Radiology 1982; 145:375-376.

30. Hsu KY, Zucherman JF, Shea WJ, Jeffrey RA. Lumbar intraspinal synovial and ganglion cysts (facet cysts). Ten-year experience in evaluation and treatment. Spine (Phila Pa 1976) 1995; 20:80-89.

31. Amoretti N, Huwart L, Foti P, Boileau P, Amoretti ME, Pellegrin A, Marcy PY, Hauger O. Symptomatic lumbar facet joint cysts treated by CT-guided intracystic and intra-articular steroid injections. Eur Radiol 2012; 22:2836-2840.

32. Koenigsberg RA. Percutaneous aspiration of lumbar synovial cyst: CT and MRI considerations. Neuroradiology 1998; 40:272-273.

33. Allen TL, Tatli Y, Lutz GE. Fluoroscopic percutaneous lumbar zygapophyseal joint cyst rupture: A clinical outcome study. Spine J 2009; 9:387-395.

34. Cambron SC, McIntyre JJ, Guerin SJ, Li Z, Pastel DA. Lumbar facet joint synovial cysts: Does $T_{2}$ signal intensity predict outcomes after percutaneous rupture? AJNR Am J Neuroradiol 2013; 34:1661-1664.

35. Ortiz AO, Tekchandani L. Improved outcomes with direct percutaneous CT guided lumbar synovial cyst treatment: Advanced approaches and techniques. J Neurointerv Surg 2014; 6:790-794.

36. Shuang F, Hou SX, Zhu JL, Ren DF, Cao $Z$, Tang JG. Percutaneous resolution of lumbar facet joint cysts as an alternative treatment to surgery: A meta-analysis. PLoS One 2014; 9:e111695. 
